\title{
Estimating the Benefits and Risks of Implementing E-Procurement
}

\author{
Peter Trkman and Kevin McCormack
}

\begin{abstract}
In recent years, organizations have invested heavily in e-procurement technology solutions. However, an estimation of the value of the technology-enabled procurement process is often lacking. Our paper presents a rigorous methodological approach to the analysis of e-procurement benefits. Business process simulations are used to analyze the benefits of both technological and organizational changes related to e-procurement. The approach enables an estimation of both the average and variability of procurement costs and benefits, workload, and lead times. In addition, the approach enables optimization of a procurement strategy (e.g., approval levels). Finally, an innovative approach to estimation of value at risk is shown.
\end{abstract}

Index Terms-Business process modeling, e-procurement, methodological approach, procure-to-pay $(\mathbf{P} 2 \mathbf{P})$ process, simulations, value at risk (VaR).

\section{INTRODUCTION}

$\mathbf{T}$ HE procure-to-pay ("P2P") process has become a major challenge to companies that have adopted global sourcing and distribution as a strategic component of their business. In recent years, organizations have adopted management practices and technologies designed to reduce transaction costs (TCs) [1], which includes the automation of $\mathrm{P} 2 \mathrm{P}$ process. E-procurement is the use of electronic means (the Internet, Web, e-mail) to enable purchases of products and services over the Internet [2], [3]. It is believed that, in addition to a decrease in costs, e-procurement also eliminates paperwork, improves data accuracy, collaboration, and transparency of the process when reducing inventory levels and lead times [4], [5].

The challenge is how to measure the increase in efficiency (both value and risks) of e-procurement implementations and simultaneous changes in the organization and strategy. Although various research and practitioner papers have dealt with the question about how to estimate the benefits of e-procurement implementation (e.g., [6] and [7]), an answer has been mainly offered based on either rough estimates without explaining the exact methodology or self-reported data from the studied companies. Both approaches have issues when estimating the potential benefits in a particular company.

Therefore, the main contribution of the approach presented in this paper is that it enables an estimation of savings based

Manuscript received June 21, 2008; revised October 9, 2008, March 10, 2009 and June 23, 2009. First published November 13, 2009; current version published April 21, 2010. Review of this manuscript was arranged by Department Editor T. Ravichandran.

P. Trkman is with the Faculty of Economics, University of Ljubljana, Kardeljeve pl. 17, 1000 Ljubljana, Slovenia (e-mail: peter.trkman@ef.uni-lj.si).

K. McCormack is with the DRK Research-A Practitioner Oriented Research Organization, Raleigh, NC 27526-8484 USA (e-mail: kmccormack@ drkresearch.org).

Color versions of one or more of the figures in this paper are available online at http://ieeexplore.ieee.org.

Digital Object Identifier 10.1109/TEM.2009.2033046 on real-life data. The main methodological approach is the simulation of business processes since the value of information technology (IT) implementation should be measured at the process level [8]. The approach also enables the recommendation of changes to an organizational structure (e.g., the appropriate approval policy). In addition, risks are estimated based on a novel application of the value-at-risk (VaR) concept. The presented calculations can be easily replicated in different practical settings with different input data.

The structure of the paper is as follows. First, the main benefits and challenges of e-procurement introduction and usage are summarized. Second, the main objectives of the study are outlined. The methodology, models, and collected data are then presented, followed by the results and analysis. Finally, the main implications and limitations of the proposed approach are outlined.

\section{E-PROCUREMENT: BENEFITS AND CHALLENGES}

Process efficiency and process integration capabilities of a procurement process provide a significant contribution to firm performance [9]. The main benefits of e-procurement are an increase in firms' competitiveness through cost reduction and/or boosted efficiency with inbound logistics [10]. These benefits can materialize in a reduction of purchasing transactions costs, order fulfillment and cycle time, a reduction of the number of suppliers or even a reduction in the price paid, and the number of staff to support purchase transactions [7]. However, in order to reap the full benefits, the business processes connected to procurement should be carefully analyzed and (if necessary) improved before it is supported with an e-procurement solution [11]. In less process mature companies, ordering and receiving are not connected, and this results to extensive manual matching and resolution before payment. Information systems are manual and decentralized, while information resides on spreadsheets in individual computers [6].

A key business process impacted by e-procurement is the $\mathrm{P} 2 \mathrm{P}$ process that encompasses activities from need specification, sourcing decision, contract-/purchase-order generation, receipt of material/documents, and finally, settlement and payment. Therefore, the paper's focus is not on the procurement department, but on the whole procurement process (as shown in Fig. 1).

Companies are increasingly considering procurement as a strategic-level concern of developing a competitive advantage [12]. Lower information exchange costs coupled with lower TCs can also make bilateral relationships more efficient and interfirm operations better coordinated, a phenomenon characterized as the integration effect of IT [13]. IT can reduce the overall TC 


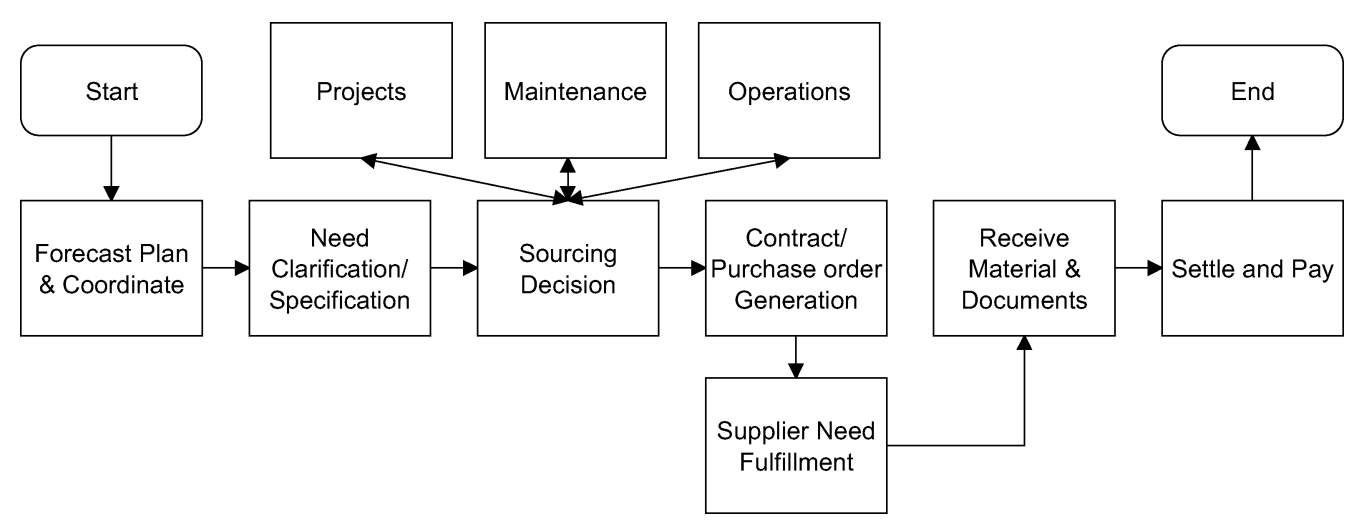

Fig. 1. Overview of the procure to pay process.

and risks associated with obtaining goods and services from suppliers [14], while also reducing the search costs connected with procurement importantly [15].

Our study includes the whole $\mathrm{P} 2 \mathrm{P}$ process, since not only order and delivery are vital, but also the activities such as receipt of invoice, approval, payment, and reconciliation can carry considerable costs and/or risks [16]. Past experience has shown that many efforts have failed because they targeted processes contained only in a single department [17].

Most importantly, the benefits, costs, and risks of IT implementation need to be identified, managed, and controlled if businesses are to derive value from their investments [18]. Despite the greater attention paid to the $\mathrm{P} 2 \mathrm{P}$, most companies are still unsure of the benefits and the ways to measure the value of the informatization of procurement, and which factors affect this value [19]. In many cases, the real benefits are not identified, resulting in companies not recognizing the true value of e-procurement [20]. A recent study showed that IT plays a significant role in everyday procurement, but the expectations of IT are rarely completely fulfilled [21].

Therefore, there is a need to better understand the value of eprocurement at a level of analysis smaller than a firm [19]. This paper analyzes its value at the level of the business process. The analysis of the intermediate outcome of e-procurement can shed more light on the efficiency of the process than financial outcome measures, such as return on assets or return on investment [3].

This is vital since so far there has been only limited effort to conceptualize the key constructs that characterize procurement as a process [12]. While the usage of technology is important, the process approach allows the identification of key organizational and other issues [11], [22]. In order to realize the benefits of e-procurement, it is necessary to properly improve the process and not simply to automate the existing methods of working [5]. Then, processes have to be continuously measured and analyzed by defining and implementing performance measures and key performance indicators [23]. Therefore, our paper conceptualizes $\mathrm{P} 2 \mathrm{P}$ as a process and proposes related performance indicators and measurements.

\section{RESEARCH OBJECTIVES}

Our approach studies both the prediction of changes due to technology implementation and organizational savings, and is line with earlier research, which found that early adopters emphasize cost reductions and administrative efficiencies from eprocurement [24]. More mature users focus on strategic advantage and generate this through organizational changes. Eprocurement impacts both a firm's primary business processes and the organizational structures used to coordinate these processes [25].

Accordingly, our analysis centers around two main questions:

1) how can the reduction of procurement cost, lead times, and employee workloads be measured and

2) which advantages and potential risks do organizational changes (in our case, a change in approval procedures) bring to the procurement process?

In relation to 1), coordination costs, such as search, negotiation, communication, follow-up, and error reconciliation with suppliers, can make up a significant part of costs and eprocurement can play a vital role in reducing such costs [19]. Earlier research found similar estimates of cost reductions due to the implementation of e-procurement. Various independent studies found that costs of manually processing a purchase order can range from U.S. dollar (USD) 100 to 250, while e-procurement can reduce these costs to around USD 10 to USD 30 [6], [16], [26], [27].

In such a way, e-procurement should lead to savings of around $42 \%-65 \%$ in purchasing TCs [7], [28]. In addition, sourcing cycling times should be reduced by $25 \%-30 \%$ and time to market by $10 \%-15 \%$. The Aberdeen research gave even higher estimates, namely a reduction of requisition-to-order cycles by $66 \%$ and a reduction of costs by $58 \%$ [29].

Obviously, all of these estimations similarly indicate relatively large savings, usually around $50 \%$ or more of total costs of the procurement process. The only significant exception is reported in [30], who claimed that e-procurement reduced TCs by approximately $99.7 \%$. However, it is likely that such a figure disregards various costs connected to e-procurement.

Despite the abundance of such studies, most of these estimations either failed to provide a methodology of their approach or used a survey/sample of self-reported benefits from studied companies for estimating the benefits. This is questionable since there is little consensus on how to gauge the value of technology-enabled procurement processes [3]. The range of these estimations is too large to be used in a practical 
setting and organization-level factors, such as spend characteristics/portfolio and internal sourcing competency, significantly affect the level of savings [31]. Further, the assumption of most of the studies is that the company will use e-procurement for all of their purchases; yet, in practice, the level of using e-procurement can be around $25 \%$ of the total value of procurements [7], [32].

These findings are difficult to replicate and test in other settings, and are of questionable validity for use as guidance for managers facing the need to estimate the benefits and justify the investment in e-procurement solutions. The justification of the costs and benefits is needed to secure enterprise funding and support [31]. Therefore, the initial objective of the paper is to provide a robust simulation-based methodology for analyzing the reduction in costs/lead times/employee workload that can be easily replicated by other companies, considering an investment in the P2P process.

In relation to 2 ), in addition to savings in procurement costs, e-procurement can change the organizational structure, responsibilities, and internal power structures simultaneously [33], and induce a change in organizational processes and culture [10]. E-procurement leads to changes at different levels, including organizational, financial, and the information systems department [10]. The structure of buying centers tends to flatten and fewer levels of management actively engage in each activity [34]. E-procurement can lead to long-term efficiency gains by fundamentally changing the coordination mechanics and transaction practices [3]. A typical example is the automatization of the approval process of senior managers by preauthorizing operating personnel [34]. As outlined earlier, these changes can bring both benefits and potential risks due to mistakes or fraud by employees. This highlights the critical need to study risk tradeoffs and gauge the business value impacts of potential shocks [35]. Therefore, the second objective of the paper is to measure both the variability of the process time and costs, and the potential risks of these changes also. The latter is measured by the VaR measure.

The hesitation to adopt e-procurement, for example, does not stem from expected difficulty or constraints, but arises due to being unaware of clear anticipated benefits [36], [37]. There is a positive relationship between beliefs about a target new technology, its usefulness, and its subsequent adoption [38], [39]. A company's vague statement of the benefits, leading to an uncertain allocation of responsibility for managing their delivery, is the number one cause of project failures [40].

However, the benefits are not the only determinants of eprocurement usage as perceived risks also play an important role. Thus, the focus should not only be on benefits for firms, but also on estimating the firms' risks or at least their perception of risks [41].

\section{Methodology}

The general approach to such analysis is shown in Fig. 2. The activities in the figure are numbered and referred to in this section. A parallel gateway (plus sign) indicates tasks that can be done simultaneously.

The main objectives (activity 1 in Fig. 2) of our analysis are outlined in the previous section. The studied process (activity
2) was a P2P process of six major companies. Each company (except one) had at least 40000 purchase orders passing through their P2P system every year. These companies were in the oil industry equipment, chemical, cement, and oil exploration and development industries. General data about the companies included are shown in Table I (the company names are fictional, all the other data are real).

In order to map the current business process (AS-IS) (activity 3), semistructured interviews with approximately 100 people from the six companies were conducted. Various procurement and IT employees at all levels of the hierarchy and in different geographical locations (field, corporate) participated in the interviews. The following employees from the studied companies were included: buyers, procurement managers, commodity managers, Directors of procurement, Directors of the supply chain, IT managers, Vice President of the supply chain, and strategic sourcing managers. The exact titles vary from company to company; the titles also depend on the maturity of the procurement process in each company. In addition, semistructured phone interviews with account managers from approximately 30-50 of the largest suppliers of each of the six studied companies were conducted.

The developed business process model is shown in Fig. 3. While the presented model is a simplified version of reality, it is sufficient for our purpose. The developed model only includes activities in the order and initiation stage, and not those involved in the search for products/suppliers. IT usage in the order and initiation stage, for example, has a more significant impact on procurement-process performance [42]. Thus, the assumption (that also matches the scope of the collected data) that the company procures from known, long-term suppliers was made (see, e.g., [43]). The process model was validated (activity 4) with company employees involved in the $\mathrm{P} 2 \mathrm{P}$ process. Further refinements were made to assure that the developed model matched the real situation in the company.

In order to collect the necessary data for the simulation (activity 5), each of the interviewees was asked to estimate the average lead time/time of each activity, along with the variability of these times. The data acquired from all the interviews were compared and refined. They were also cross-checked with the data acquired from the SAP system. Descriptive statistics (frequency, mean, standard deviation, distributions, etc.) were used to examine the types of orders (procurement card (PCard), e-catalog, and buyer assisted) for each company's process. A lognormal distribution was used for sampling the times of activities because it is a sufficiently flexible theoretical probability distribution for modeling operation times in procurement [44]. Descriptive statistics for the simulation study are included in Table II and only the data for one company are shown; however, the data for the others are quite similar.

All companies were similar in the activities and duration, since they all had the same enterprise resource planning software, namely SAP, as their procurement system. Although the use of the same software does not automatically mean the use of same processes or process execution efficiency, in our case, their processes were built around the SAP recommendations. Enterprise resource planning implementation, for example, 


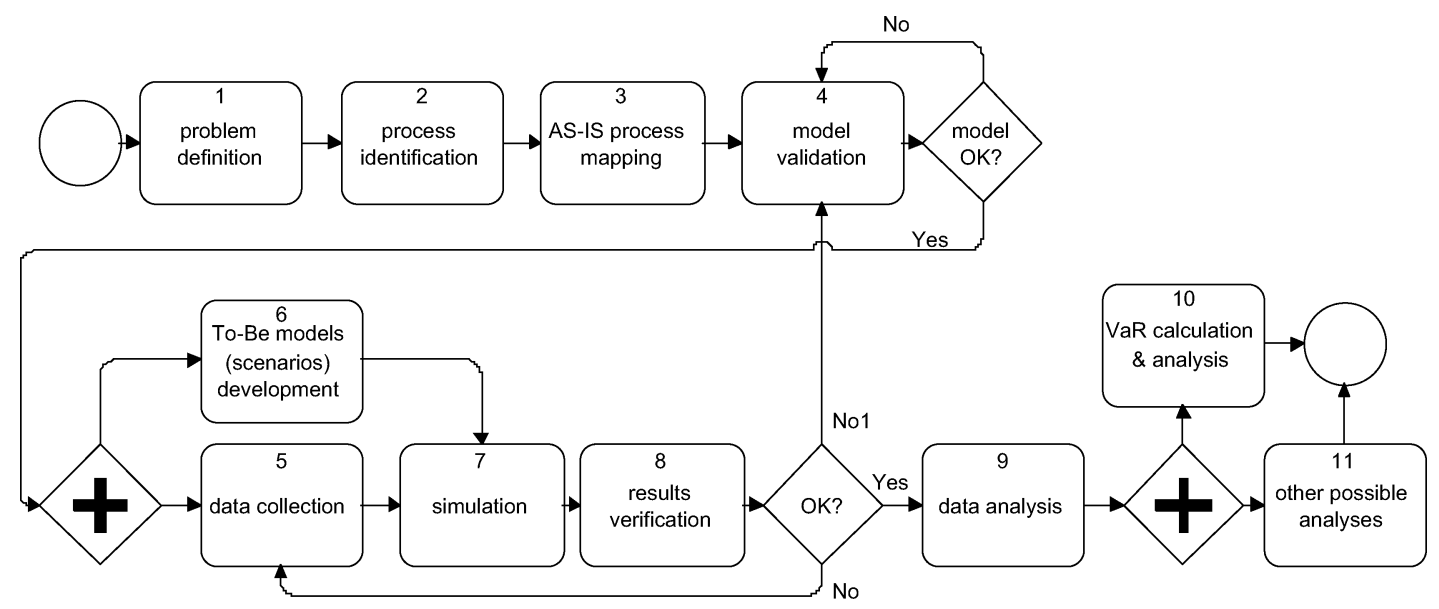

Fig. 2. Flowchart of the project.

TABLE I

CHARACTERISTICS OF THE STUdIED COMPANIES

\begin{tabular}{|l|r|l|l|r|}
\hline Company Name & $\begin{array}{l}\text { Sales (per Year in } \\
\text { Million \$) }\end{array}$ & Headquarters & Industry/Products & $\begin{array}{l}\text { No. of Purchase } \\
\text { Orders per Year } \\
\text { (Approx.) }\end{array}$ \\
\hline Chemicalia & 3500 & Houston, TX & $\begin{array}{l}\text { Poly propylene, poly } \\
\text { ethylene resins }\end{array}$ & 85,000 \\
\hline Judril & 250 & Houston, TX & $\begin{array}{l}\text { Skid-mounted drilling, } \\
\text { equipment to oil field }\end{array}$ & 48,000 \\
\hline Cementy & 500 & Nazareth, PA & Cement & $\begin{array}{l}\text { Oil sands mining and } \\
\text { production }\end{array}$ \\
\hline Energy & Company & Multibillion & Switzerland & $\begin{array}{l}\text { Various chemicals and } \\
\text { resins }\end{array}$ \\
\hline Polymerco & Multibillion & Houston, TX & Gas pipeline company & 52,0000 \\
\hline Energocom & &
\end{tabular}

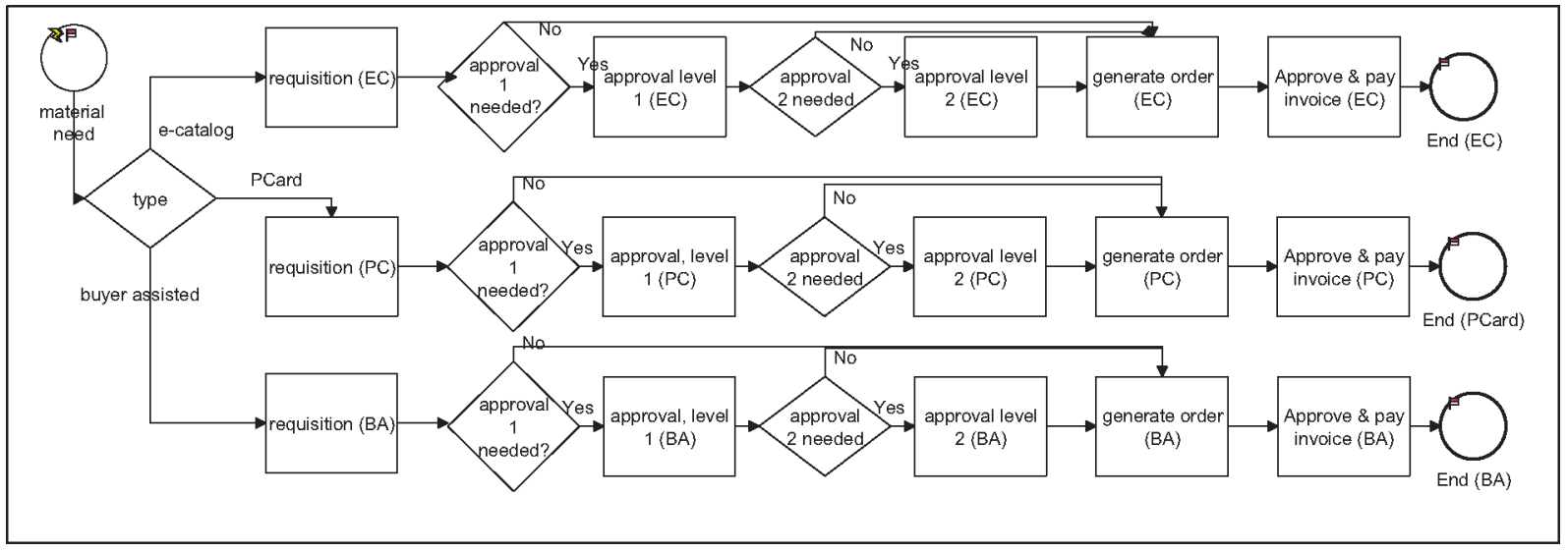

Fig. 3. P2P business process model. 
TABLE II

LeAD TIME OF THE Main ACTIVITIES IN the P2P PROCESS

\begin{tabular}{lcrrrrrr}
\hline Activity & $\begin{array}{l}\text { Mean } \\
\text { (in hrs) }\end{array}$ & $\begin{array}{l}\text { Deviation } \\
\text { (in hrs) }\end{array}$ & $\begin{array}{l}\text { Mean } \\
\text { (in } \\
\text { hrs) }\end{array}$ & $\begin{array}{l}\text { Deviation } \\
\text { (in hrs) }\end{array}$ & $\begin{array}{l}\text { Mean } \\
\text { (in } \\
\text { hrs) }\end{array}$ & $\begin{array}{l}\text { Deviation } \\
\text { (in hrs) }\end{array}$ \\
\hline Type of Transaction & \multicolumn{2}{c}{ PCard } & \multicolumn{2}{c}{ E-catalog } & \multicolumn{2}{c}{ Buyer-assisted } \\
\hline Requisition & 0.1 & 0.01 & 0.2 & 0.1 & 5 & 2 \\
\hline Approval, level 1 & 2 & 0.2 & 2 & 0.4 & 2 & 1 \\
\hline Approval, level 2 & 3 & 0.3 & 3 & 0.6 & 3 & 1 \\
\hline Generate Order & 0.1 & 0.01 & 0.1 & 0.02 & 2 & 0.5 \\
\hline Approve \& pay invoice & 0.1 & 0.01 & 0.2 & 0.04 & 3 & 0.5 \\
\hline
\end{tabular}

TABLE III

AVERAGE LEAD TIME AND TOTAL FTES FOR EACH SCENARIO

\begin{tabular}{lrrrrrr}
\hline Scenario & $\begin{array}{c}\text { Avg. Lead } \\
\text { Times (in } \\
\text { Days) }\end{array}$ & $\begin{array}{c}\text { Lead Time } \\
\text { Index (Scen 1 } \\
=100)\end{array}$ & $\begin{array}{c}\text { Avg. } \\
\text { Procurement } \\
\text { Costs in USD }\end{array}$ & $\begin{array}{c}\text { Procurement } \\
\text { Officers (FTE) }\end{array}$ & $\begin{array}{c}\text { Supervisor } \\
\text { Time (FTE) }\end{array}$ & $\begin{array}{c}\text { Top } \\
\text { Management } \\
\text { Time (FTE) }\end{array}$ \\
\hline Scen1 & 11.3 & 100 & 181 & 50.7 & 6.8 & 0.08 \\
\hline Scen2 & 9.4 & 83 & 155 & 41.7 & 6.8 & 0.08 \\
\hline Scen3 & 8.4 & 74 & 125 & 31.8 & 6.8 & 0.08 \\
\hline Scen4 & 7.6 & 67 & 135 & 41.7 & 2.5 & 0 \\
\hline
\end{tabular}

requires the reengineering of a business process prior to the adoption of Enterprise Resource Planning (ERP), and the company usually accepts the proposed standard business processes from ERP [45]. Since our business process model (Fig. 3) is intentionally rather general, it can be applied to all studied companies. If a company would have considerably different P2P process, the whole approach (shown in Fig. 2) should be repeated.

Based on data from Judril, the value of each order was estimated as an exponential distribution with the mean of USD 2000. The current approval levels are that all orders above USD 1000 have to be approved by the supervisor (approval level 1). All orders above USD 10000 have to be approved by both the supervisor and the senior manager (approval level 2).

Different scenarios for process redesign and informatization (activity 6) were prepared. The main objective of improving the $\mathrm{P} 2 \mathrm{P}$ process was to replace some of the high-cost buyer-assisted orders by introducing both an electronic catalog (e-catalog) and a PCard.

The e-catalog is one of the most widely used e-procurement technologies and usually contains specifications and prices of all products obtained from contracted suppliers. Suppliers can directly access the enterprise server and update information about their products and services [5], [10], [46]. A PCard is an electronic transaction card issued at the firm level and intended for small value transaction, noninventory/stock, and noncapital purchases. The advantage of PCards is the ease with which they can be implemented and the low initial cash investment [7], [47].

The analysis examines the following four scenarios (they were chosen since they are the most typical situations encountered in the real world [32], [48]).

1) Scenario 1 (scen1): All orders (100\%) are buyer-assisted.
2) Scenario 2 (scen2): $80 \%$ of orders are buyer-assisted, while $10 \%$ of orders are made with a Pcard, while for $10 \%$ of orders an e-catalog is used.

3) Scenario 3 (scen3): As the use of new procurement techniques increases, only $60 \%$ of orders are buyer-assisted, while the PCard/e-catalog are used in 30\%/10\% of cases.

4) Scenario 4 (scen4): The level of automation is the same as in scen $2(80 \%, 10 \%, 10 \%)$. However, due to the empowerment of the employees and organizational changes, the approval levels are tripled.

Discrete-event simulations (activity 7) were used to analyze different scenarios. The reason is that the adoption of rigorous business process simulation methodologies enables one to evaluate different configuration of process chains in realistic settings and estimate the expected payoffs resulting from reengineering/IT incorporation [49]-[52].

The main problem of simulations can be the large costs and amount of time needed [53]. It is, therefore, often too expensive for small- and medium-sized companies to build simulation competence within the company, especially due to the high expenditure on specific know-how [54]. Further, it should not be forgotten that the models developed are always a simplification of a real system under examination.

In our case, the Igrafx Process 2007 was used. It is one of the most widely used simulation tools [55], which enables our approach to be repeated in a practical setting. Similar methodological approaches were successfully used in the past to measure the effects of a business process improvement in public administration [56], supply chains [11], and production processes [57]. A 12-month simulation was run, which amounted to approximately 33000 orders. The time between each transaction (order) is randomly distributed. In addition to process models and data 
from each of the four scenarios, the following input variables were used: duration of each activity and its variability, number and distribution of transaction, and value of each transaction. The main outputs were the lead time and cost of each transaction, and the full-time equivalents (FTEs) required at each working position (e.g., procurement worker and supervisor).

The validation and verification of the obtained outputs are vital [58]. In our case, the outputs were first validated with company employees. In addition, the results were cross-checked with data from SAP, expert opinions, and previous research results. If a large discrepancy is found, it may be necessary to correct the developed process model (activity 3 ) or recheck the collected data (activity 5). The data (value of transaction, work, and delay time of each activity, etc.) about each simulated transaction were recorded for further analyses. The collected data enabled an analysis of both average times and costs, and their distribution and the application of the VaR concept.

Finally, all results were exported to MS Excel where they were analyzed (activity 9; results presented in the next section). Finally, additional assumptions were made in order to acquire the probabilistic distribution required to calculate the VaR (activity 10; results are presented in the next section). If required, a further analysis (including the use of other simulation tools) could be undertaken (activity 11).

\section{RESUltS AND ANALYSIS}

While the proposed methodology enables an estimation of different aspects, our analysis focuses on the main critical success factors of implementing e-procurement, namely the costs, lead times, and risks. The following are the chief results of the simulations.

1) TCs-Measured by costs of employees' work (FTE) in the following functions: "Procurement worker," "supervisor, and "top manager." An estimation of total costs (in USD) is also calculated based on the assumption that the FTE cost is USD 100000 for each procurement worker, USD 150000 for a supervisor, and USD 300000 for a top manager. These figures are based on our interviews and in line with recent research [59].

2) Lead (cycle) time: A lead-time reduction is important since it allows the lowering of safety stock requirements and improving of customer service [60]. In addition, the variability in process outcomes is connected to uncertainty and risks. Process uncertainty is likely to be reflected in late deliveries and poor quality performance, so both fast and reliable deliveries are vital [61]. Both the average and distributions of lead times for each scenario were examined.

3) VaR: A novel application of $\mathrm{VaR}$ is proposed in order to estimate the potential risk exposure due to organizational changes. VaR is defined as the expected loss arising from an adverse market movement with a specified probability over a period of time [62]. While VaR was primarily intended to measure the risk of exposure in the financial industry [63], [64], it has been not applied to a great extent to engineering systems, in general, and supply chain/procurement in particular [65]. Such an approach may help a company estimate the highest possible risk (at certain probabilities) that it may be exposed to.

While the Supply Chain Council defined VaR in eprocurement as the sum of the probability of events times the monetary impact of the events for the specific process, supplier, product, or customer [66], no approach to its measurement was presented. It was also claimed that calculating VaR from historical data requires a large database of events and metrics, and can be computationally intensive [66]. Since it seems that the importance of VaR estimation (see usage in, e.g., [62], [65], and [67]) in the supply-chain management context is increasing, it is important to develop more sophisticated approaches to its measurement. Our approach is an initial, yet important step in this direction.

The aggregated results are shown in Table III. The average lead time decreases with the increase in automation (17\% for scen2; $26 \%$ for scen 3 ), while the average costs for orders and the number of procurement workers dropped considerably (e.g., from 51 in scen 1 to 32 in the third scenario), with the automation of approximately half the orders. This finding is in line with the fact that IT plays a vital role in eliminating the need for human resources to perform routine purchasing tasks [68], and therefore, online procurement is significantly positively correlated with a higher productivity growth rate [33].

The comparison of scen 3 and scen 4 offers interesting insights. Both scens 3 and 4 are upgrades of scen2. The difference is that scen 3 focuses on further information support (a larger percent of automated orders), while scen 4 focuses on organizational changes (a lower number of approvals needed). As shown in Table III, both scenarios contribute to a further decrease in both costs and lead times (compared to scen2); however, scen3 contributes more to the decrease in costs. IT support has mainly decreased the costs/workload of employees, while the organizational changes in scen 4 (change in approval levels) considerably reduce the lead time due to the elimination of waiting for supervisor/manager approval. It also contributed to a decrease in costs (compared to scen2), but not so much as scen3.

These results are in line with earlier studies, which may indicate (although not prove) that the simulation model is correct and it can be repeated (with different data) in other companies. Some of the estimates of costs and lead times are slightly lower--this is because we only studied a partial transition toward e-procurement with the automatization of a certain percentage of orders, which is a more realistic case in practice.

However, the average lead times only reveal part of the story. The variability of lead times also has to be studied since it can pose even greater problems at the supply-chain level. It is often claimed that the core goal of problem solving in procurement/supply chain management is to reduce uncertainties [69], [70]. Companies usually respond to time variability by increasing time buffers, which is reasonable and easy to use, yet highly inefficient [71]. The probabilistic distribution of lead times for all four scenarios is shown in Fig. 4, while Table IV shows the likelihood that the lead time of a certain order will be shorter than 8/14 days. For example, for scenario 1, the likelihood that the lead time of the transaction would be eight days or 


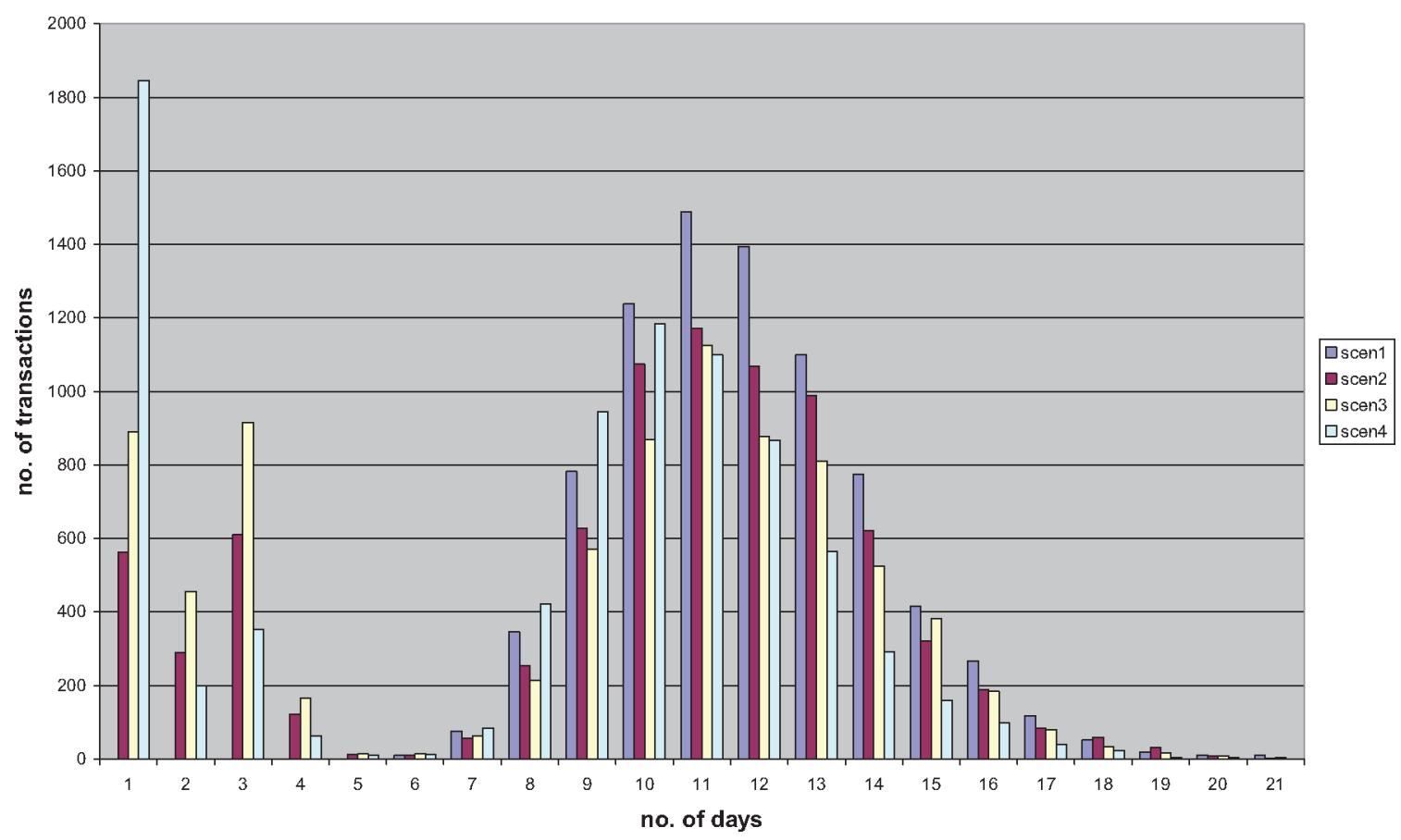

Fig. 4. Probabilistic distribution of the lead times of transactions (all four scenarios).

TABLE IV

Probabilities That a Transaction Will Finish Within a Given Period OF TIME

\section{Likelihood of Completion within the Given Time}

Time of Completion Scen1 Scen2 Scen3 Scen4

\begin{tabular}{lrrrr}
\hline 8 Days or less & $5 \%$ & $23 \%$ & $33 \%$ & $36 \%$ \\
\hline 14 Days or less & $89 \%$ & $91 \%$ & $91 \%$ & $96 \%$ \\
\hline
\end{tabular}

less is 5\% (with an $89 \%$ likelihood that it would be shorter than 14 days, meaning that $84 \%$ of transactions would take between 8 and 15 days). For, e.g., scenario 4 (where the expected lead time is much shorter), the likelihood of filling an order within five days is $36 \%$ (and $96 \%$ for 14 days).

The results are important for companies that plan their inventory safety levels based on expected lead times. Since the technological and organizational changes reduced both the lead time and its variability, it is logical that the likelihood of executing an order within the 8/14-day time period is larger for scen2-scen 4 and the occurrence of out-of-stock situations is lower (assuming that the safety buffers are unchanged). If, for example, a company uses a 14-day time buffer, it can be assumed that it will run out of stock during 11\% (scen1), 9\% (scen2), 9\% (scen3), and $4 \%$ (scen 4$)$ of the orders.

While the value of orders for the simulation was estimated based on the data from Judril, the input data of two companies were also analyzed (Cementy with 36440 orders and Chemicalia with 50612 orders in the database). The main difference was found in the distribution of the value of orders. Cementy mainly had a larger number of smaller orders-only $0.31 \%$ orders over
USD 100000 (still amounting to 51.8\% of the total procured value) and 3.22\% over USD 10000 (72.1\% of the total procured value). On the other hand, Chemicalia had several large orders. $4.0 \%$ orders ( $95.6 \%$ of the total value) of their orders were over USD 100000 and $12.0 \%$ order over USD 10000 (99.2\% of the total value).

Simulation wise, this means that (all other things equal) the lead times (shown in, e.g., Fig. 4 for Judril) of Chemicalia are slightly longer and differently distributed (with a larger "long tail" on the right) than those of Judril especially. This is due to a longer approval process (more orders need to be approved). Similarly, the approval costs (shown in Table III for Judril) are higher. A number of large orders also increases the VaR due to a higher possible impact due to problems with a few large orders.

As can be seen from the distributions, introduction of the PCard and e-catalog does allow the quick processing of some purchase orders. It also considerably decreases the average lead time. However, their introduction does not considerably affect the long tail—orders that last 14 days or more. These results confirm the finding that at a lower level of process maturity, the $\mathrm{P} 2 \mathrm{P}$ process uses some automation, but is still unpredictable with over half of the purchases in a time-consuming process that is largely uncontrolled [6].

Organizational changes, namely the empowerment of the employees (scen4; tripling their authorization level) achieves all of the aforementioned. In addition to shorter average lead times, the number of transactions with extremely long lead times is reduced. Also, the workload of managers/supervisors is reduced, allowing them to focus more on value-added activities. The average costs and the number of purchasing workers do not change considerably since they still perform the same tasks (but their waiting for approvals that caused delays is considerably reduced). 
TABLE V

Total Value of Transactions That Did Not NeEd Approval LeVels 1 and 2

\begin{tabular}{lrrr}
\hline & Scen1-Scen3 (USD) & Scen4 (USD) & Increase \\
\hline Without Approval Level 1 & $6,046,500$ & $29,777,812$ & $392 \%$ \\
\hline Without Approval Level 2 & $64,777,926$ & $67,608,646$ & $4 \%$ \\
\hline
\end{tabular}

However, such changes also bring potential risks. Table $\mathrm{V}$ shows a considerable increase in the value of transactions with no supervisor approval. The value of transactions with no approval increases by $392 \%$ and the value of transactions without approval level 2 increases by $4 \%$. This shows that the reduction in lead time was mostly realized through the elimination of middle management (approval level 1). This is in line with the finding that e-procurement can drastically reduce the number of middle managers needed (see, e.g., [72]) and waiting for approval can considerably extend the lead times when not having a large impact on TCs [73]. However, it may pose risks of wrong orders emerging due to mistakes (or even fraud) by procurement workers.

Therefore, an additional analysis was conducted on the assumption that lower approval levels increase the chance of a loss due to mistakes/incorrect orders. Assuming that the value of employees' mistakes is the following percentage of each order:

1) $3 \%$ (2\% standard deviation; left truncated at $0 \%$ ) if the order is not authorized;

2) $1.5 \%(0.5 \%$ standard deviation; left truncated at $0 \%)$ if the order receives authorization from the supervisor; and

3) $0.5 \%(0.2 \%$ standard deviation; left truncated at $0 \%)$ if the order receives authorization from both the supervisor and the top manager.

Table VI and Fig. 5 show the simulated total costs as the sum of approval and wrong order costs for various approval levels. The $x$ scale is indexed with the current approval costs having the index 100. Approval costs (the dotted line in Fig. 5) are the cost of the work of the supervisor/top managers. Value loss costs (the dashed line) are the costs arising due to wrong orders. Total costs (the solid line) are the sum of both.

A high level (or nonexisting level) of approval obviously leads to a laissez-faire organization, where most orders are made without any supervision. This obviously means low approval costs but a high value loss due to wrong orders. On the other hand, a low approval level (a very bureaucratic organization) reduces the number of wrong orders but drastically increases the approval costs.

First, such an approach enables an analysis of the impact of changes in approval level on approval and value loss costs. In our case, a $10 \%$ increase in the approval level brings a $5 \%$ decrease in approval costs and a $2 \%$ increase in value loss; a $10 \%$ decrease would bring an $8 \%$ increase in approval costs and a $3 \%$ decrease in value loss. In such a way, the optimal approval level can also be found, namely where the total costs are the lowest. In our example, it is reached with a $250 \%$ increase in the approval level (index 350). Obviously, these results should only be used as guidance in decision making as they are only an estimation of the tradeoff between benefits and risks (as also shown with the VaR calculation in the continuation of the paper).
Obviously, the numerical results of this experiment cannot be generalized to all companies since they will have different productivity profiles [74]. Savings, realized by other adopters, do not ensure substantial cost savings for every firm [31]. However, a similar approach (with different data) can be repeated for most companies. The simulation model is also flexible enough to be extended with the inclusion of other sorts of costs, if necessary.

Further, VaR was also calculated from the results of all simulations. First, the difference between value loss and VaR needs to be defined; the value loss is a simple arithmetic average, meaning the expected average loss in the process (in our case, due to mistakes and the fraud of employees). However, the VaR calculation demands the probabilistic distribution of potential outcomes; in our case, a normal distribution of the employees' mistakes was assumed (as outlined earlier). Other distributions could also be used with the same approach to the VaR calculation. A standard normal table for the normal distribution was used to calculate the threshold (from all simulated data), which constitutes the VaR at $95 \%(99 \%)$. This is the dollar value from which $95 \%$ (99\%) of expected losses in different realizations of the simulation are lower (this is the $95 \%$ and $99 \%$ percentiles from the distribution).

The approach to the VaR calculation, in general, is that the probabilistic distribution of potential losses needs to be generated first. This can be either with a similar simulation-based approach as found in this paper or with one of the other methods that consider the likelihood of various events and their impact (see, e.g., [75]); e.g., the data could also be obtained from interviews with procurement workers and managers. After the creation of such a distribution, the dividing line between, e.g., $95 \%$ of lower and $5 \%$ of higher values should be taken as a VaR at $95 \%$. Table VII shows the increase of VaR in the case of the empowerment of employees (scen4 versus scen2).

It should be emphasized that VaR does not measure the expected losses but the probable maximum losses that a company may accrue with a certain strategy. The number USD 2052932 means that (in scen2) there is a $95 \%$ chance that the loss due to wrong orders will be below this amount. In scen4, the loss due to wrong orders will be below USD 3740071 (with a 95\% probability). This example clearly illustrates the tradeoff: lower control costs mean a higher VaR and consequently higher risks.

The main limitation of the VaR approach is that it is a rather simplistic approach and provides an insight into expected losses in "normal" business conditions, but is inappropriate for analyzing the impact of truly catastrophic events with a low probability [76]. Generally, organizations plan to protect themselves against recurrent, low-impact risks in their supply chains, but ignore high-impact, low-likelihood risks [77], [78]. In our example, the costs due to supplier bankruptcy or employee fraud are not included. In order to include these risks also, the VaR 
TABLE VI

TOTAL PROCUREMENT COSTS FOR DIFFERENT APPROVAL LEVELS

\begin{tabular}{rrrrrrr}
\hline $\begin{array}{c}\text { Approval } \\
1 \\
\text { (Indexed) }\end{array}$ & $\begin{array}{c}\text { Approval } \\
\text { (Indexed) }\end{array}$ & $\begin{array}{c}\text { Supervisor } \\
\text { Workload } \\
\text { (FTE) }\end{array}$ & $\begin{array}{c}\text { Manager } \\
\text { Workload } \\
\text { (FTE) }\end{array}$ & $\begin{array}{c}\text { Approval } \\
\text { Costs (USD) }\end{array}$ & $\begin{array}{c}\text { Value Loss } \\
\text { Costs (USD) }\end{array}$ & $\begin{array}{c}\text { Total Costs } \\
\text { (USD) }\end{array}$ \\
\hline 10 & 10 & 10.6 & 6.70 & $3,625,000$ & 397,276 & $4,022,276$ \\
\hline 50 & 50 & 8.7 & 0.94 & $1,589,300$ & 844,015 & $2,433,315$ \\
\hline 100 & 100 & 6.8 & 0.08 & $1,049,500$ & $1,078,234$ & $2,127,734$ \\
\hline 300 & 300 & 2.5 & 0 & 379,400 & $1,466,992$ & $1,846,392$ \\
\hline 500 & 500 & 0.94 & 0 & 142,100 & $1,743,300$ & $1,885,400$ \\
\hline 1000 & 1000 & 0.08 & 0 & 12,000 & $2,000,453$ & $2,012,453$ \\
\hline
\end{tabular}

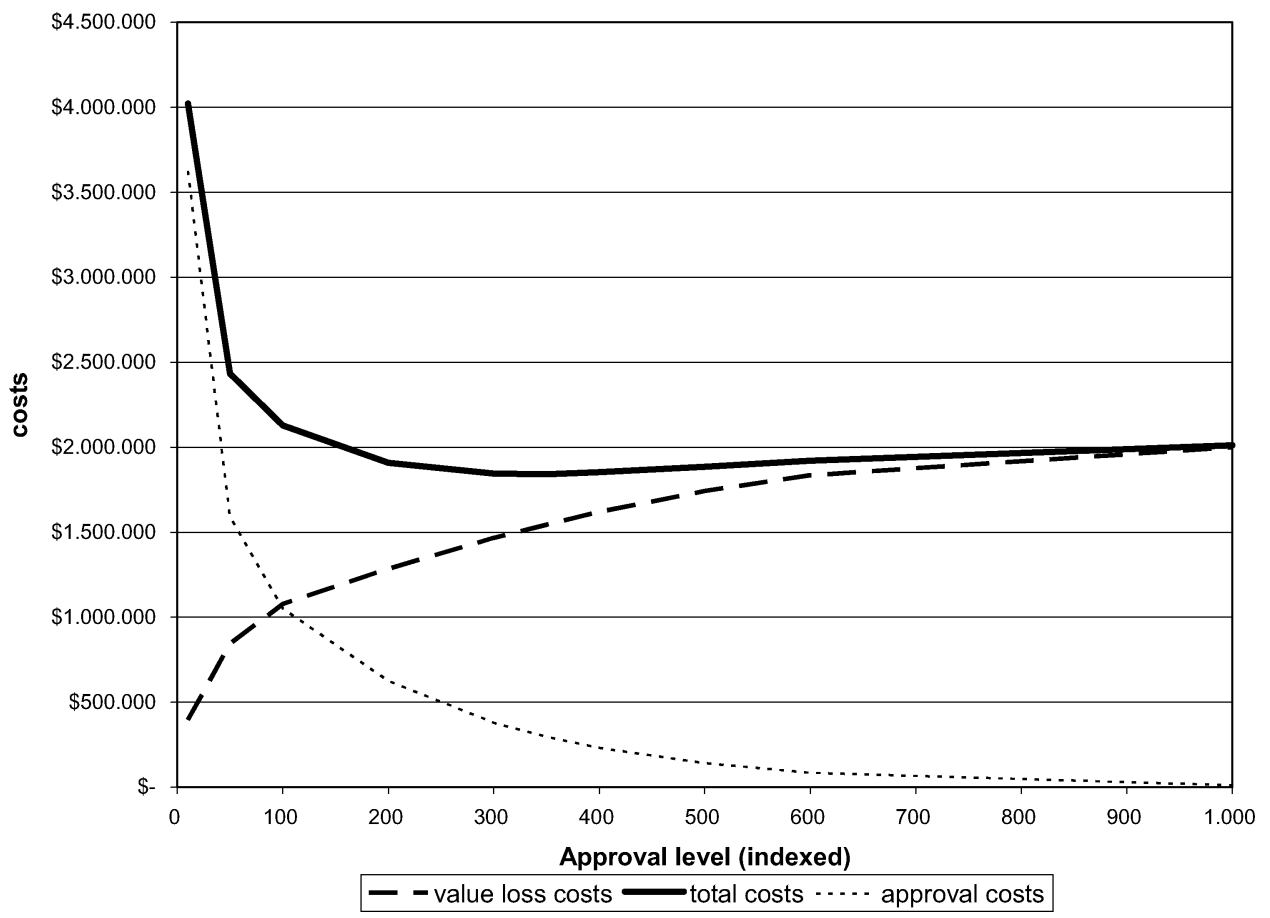

Fig. 5. Procurement costs (approval, depending on the value of approval level 1).

TABLE VII

VAR OF THE DIFFERENT SCENARIOS

\begin{tabular}{lrrr}
\hline Scenario & $\begin{array}{c}\text { Approval/Check } \\
\text { Costs in USD }\end{array}$ & $\begin{array}{c}\text { VaR (95\% Probability) } \\
\text { in USD }\end{array}$ & $\begin{array}{c}\text { VaR (99\% } \\
\text { Probability) in USD }\end{array}$ \\
\hline Scen2: More control & $1,049,500$ & $2,052,932$ & $2,330,755$ \\
\hline $\begin{array}{l}\text { Scen4: Empowerment of } \\
\text { employees }\end{array}$ & 379,400 & $3,740,071$ & $4,315,433$ \\
\hline
\end{tabular}

approach should be complemented with other risk-management practices (see, e.g., [75]).

\section{DISCUSSION AND CONCLUSION}

The procurement process is one of the most important processes, and its costs, reliability, and risks considerably influence the performance or even survival of a company. Still, many companies lack an approach to rigorously and quantitatively evaluate their options, benefits, and risk. First of all, such an approach must include the whole $\mathrm{P} 2 \mathrm{P}$ process that usually spans various departments and managerial levels. However, it was often found that local optima do not lead to a global optimum (e.g., [79]), and past experience has shown that many efforts have failed because they targeted processes contained only in a single department [17]. Therefore, our approach is holistic and includes the whole P2P process.

Further, due to differences in procurement processes, activity times, and the number and relations with suppliers, self-reported average results cannot be applied in process redesign and 
e-procurement technology implementation in a specific company. A company should carefully analyze its own business processes and procurement transactions, and use suitable criteria (e.g., costs, risks, lead time, and percentage of transactions beyond a certain threshold). Both the criteria and the simulation/process model can be properly modified without much trouble.

In the event, another studied company was to have a slightly different procurement process and the process/simulation model should also be properly adapted. The process model (Fig. 3) is developed broadly enough to serve as a reusable framework that can be applied to other similar procurement processes with the application of the approach shown in Fig. 2. However, the approach is unsuitable for companies that rely on automated ordering with the use of just in time, vendor management inventory, or similar concepts. Such an approach is often found in, e.g., the automotive industry.

Therefore, the paper's main contribution is its presentation of a methodological approach to the measurement of risks and benefits of implementing e-procurement with an analysis of different scenarios. The results show that the same decrease in costs and lead times does not necessarily happen simultaneously, and organizational changes/process improvement can often bring even greater savings than implementation of a simple technology. The results can be used as benchmark/key performance indicators for monitoring an e-procurement implementation project.

A novel approach to the optimization of an organizational strategy (e.g., approval level) is also presented and enables the finding of the optimal point in a tradeoff between the costs of approval procedures and the potential costs due to mistakes or fraud in the case the procedure is simplified. Business process models and simulations enable an ex ante analysis of the impact of such changes, before any changes are actually made.

The presented approach is most suitable for a company on either level 2 (defined) or level 3 (linked) of a five-level process maturity model-most companies are currently on these levels [80]. Such companies have both the required data and the developed process maps needed for the preparation of the simulation model. Companies on level 1 ( $a d$ hoc) usually do not possess detailed enough data about each activity/process, process maps, or metrics at the process level. Companies on level 4 or 5 take their cooperation with suppliers to the process level and the model in Fig. 1 should be expanded to integrate suppliers' activities (see, e.g., [11]).

Since risks in e-procurement are also important, the novel application of the VaR concept in procurement research can enable the monitoring of these risks and (if necessary) the justification of the acceptance of mitigatory actions. The paper namely presents one of the first approaches to measure the VaR of the procurement process in monetary terms. The use of VaR can also improve benchmarking between processes and companies, and contribute to the development of a common language for studying procurement risks.

The approach has several managerial implications. It can serve both in the project preparation (to estimate the potential benefits and justify the investment; additionally, the pre- conceived notion of the benefits effects the adoption of eprocurement) and the implementation phase (to monitor the project and the achievement of expected benefits). The results are explained in the terminology commonly accepted by financial managers (e.g., costs in dollars, FTE, VaR). It confirms the possibility to establish a conceptual link between financial concepts and process management [62]. Further, the results from process modeling and simulation can serve as inputs for the use of activity-based costing [81].

The research has various limitations. First, the procurement process scenarios were deliberately simplified in order to allow a focus on the main problems and minimize interaction effects that may mask the results for that scenario. They do not include the suppliers' activities, their connection to the buyer, and the potential delays or disruptions due to problems in the suppliers' internal business processes or transport routes.

The preparedness of suppliers to implement joint eprocurement solutions should also be studied. The calculation of VaR only included the probabilistic distribution of the percentage of employees' mistakes in the calculation. In order to provide a comprehensive estimation of risks, external risks should also be included (e.g., logistics problems, supplier nonperformance).

Also, the research only focused on an estimation of process costs but not on possible changes in purchase prices due to implementing e-procurement. Depending on the type of product, the savings can range between $7 \%$ and $17 \%$ [29], [82]. Our approach also did not include an estimate of the investment costs (both capital investment in technology and the necessary effort and costs of changes in the organizational structure and employees' roles) and the costs of operating and maintaining the e-procurement system.

While our study did not use underlying theory, the proposed approach enables further investigations within either TCs or information processing (IP) view theory. The TC theory is namely the most frequently applied theory in e-procurement studies [2]. Specifically, the ability to estimate both TC and the risks of eprocurement enables the utilization of risk-augmented TC theory [35] to analyze the effects of organizational changes (e.g., the empowerment of employees and reduction of middle management) on both TCs and risks.

Alternatively, the IP view of interorganizational coordination [83] could be used to assess which process configuration is most suitable for collecting and processing information. IP needs are assessed based on various characteristics of the product and procurement environment, while IP capabilities are assessed by the level of IT support for various activities in the procurement life cycle [84]. Simulation results can be used for that purpose: variability of lead times/costs can be a proxy for uncertainty, while different scenarios analyze the effects of different levels of IT support.

\section{ACKNOWLEDGMENT}

The authors would like to thank the Department Editor Dr. Ravichandran and the two anonymous referees for their several 
useful comments that improved both the content and presentation of the paper.

\section{REFERENCES}

[1] J. Hartley, M. Lane, and Y. Hong, "An exploration of the adoption of E-auctions in supply management," IEEE Trans. Eng. Manag., vol. 51, no. 2, pp. 153-161, May 2004.

[2] T. Schoenherr and R. Tummala, "Electronic procurement: A structured literature review and directions for future research," Int. J. Procurement Manage., vol. 1, pp. 8-37, 2007.

[3] F. Wu, G. A. Zsidisin, and A. Ross, "Antecedents and outcomes of Eprocurement adoption: An integrative model," IEEE Trans. Eng. Manag., vol. 54, no. 3, pp. 576-587, Aug. 2007.

[4] Y.-W. Yu, H.-C. Yu, H. Itoga, and T.-R. Lin, "Decision-making factors for effective industrial e-procurement," Technol. Soc., vol. 30, pp. 163-169, 2008.

[5] T. M. Rajkumar, "E-Procurement: Business and technical issues," Inf Syst. Manage, , vol. 18, pp. 1-9, 2001.

[6] R. Handfield, K. McCormack, and W. Steininger, "Best practices in procure to pay," NC State University, Raleigh, 2005.

[7] A. Davila, M. Gupta, and R. Palmer, "Moving procurement systems to the internet: The adoption and use of e-procurement technology models," Eur. Manage. J., vol. 21, pp. 11-23, 2003.

[8] P. Davamanirajan, R. Kauffman, C. Kriebel, and T. Mukhopadhyayd, "Systems design, process performance, and economic outcomes in international banking," J. Manage., vol. 23, pp. 65-90, 2006.

[9] A. Ordanini and G. Rubera, "Strategic capabilities and internet resources in procurement: A resource-based view of B-to-B buying process," Int J. Oper. Product. Manage., vol. 28, pp. 27-52, 2008.

[10] A. Soares-Aguiar and A. Palma-dos-Reis, "Why do firms adopt eprocurement systems? Using logistic regression to empirically test a conceptual model," IEEE Trans. Eng. Manag., vol. 55, no. 1, pp. 120-133, Feb. 2008.

[11] P. Trkman, M. I. Štemberger, J. Jaklič, and A. Groznik, "Process approach to supply chain integration," Supply Chain Manage.-Int. J., vol. 12, pp. 116-128, 2007.

[12] G. Hunter, M. Bunn, and W. Perreault, "Interrelationships among key aspects of the organizational procurement process," Int. J. Res. Marketing, vol. 23, pp. 155-170, 2006.

[13] T. Ravichandran, S. Pant, and D. Chatterjee, "Impact of industry structure and product characteristics on the structure of B2B vertical hubs," IEEE Trans. Eng. Manag., vol. 54, no. 3, pp. 506-521, Aug. 2007.

[14] L. Ellram and G. A. Zsidisin, "Factors that drive purchasing and supply management's use of information technology," IEEE Trans. Eng. Manag., vol. 49, no. 3, pp. 269-281, Aug. 2002.

[15] J. Y. Bakos, "Reducing buyer search costs: implications for electronic marketplaces," Manage. Sci., vol. 43, pp. 1676-1692, 1997.

[16] S. Dunlap, "The last unautomated frontier: How technology is streamlining the invoice-to-cash process," AFP Exch., vol. 2005, pp. 14-17, 2005.

[17] A. Spanyi, More for Less: The Power of Process Management. Tampa, FL: Meghan-Kiffer Press, 2007.

[18] P. E. D. Love, Z. Irani, C. Standing, C. Lin, and J. M. Burn, "The enigma of evaluation: Benefits, costs and risks of IT in Australian small-mediumsized enterprises," Inf. Manage., vol. 42, pp. 947-964, 2005.

[19] C. Subramaniam and M. Shaw, "The effects of process characteristics on the value of B2B E-procurement," Inf. Technol. Manage., vol. 5, pp. 161$180,2004$.

[20] A. Gunasekaran and E. W. T. Ngai, "Adoption of e-procurement in Hong Kong: An empirical research,” Int. J. Product. Econ., vol. 113, pp. 159175,2008

[21] C. Tanner, R. Wolfle, P. Schubert, and M. Quade, "Current trends and challenges in electronic procurement: An empirical study," Electron. Markets, vol. 18, pp. 6-18, 2008.

[22] K. Reeves, "Supply chain governance: A case of cross dock management in the automotive industry," IEEE Trans. Eng. Manag., vol. 54, no. 3, pp. 455-467, Aug. 2007.

[23] K. McCormack, Business Process Maturity: Theory and Application. North Charleston, SC: Booksurge LLC, 2007.

[24] C. Ash and J. Burn, "Assessing the benefits from e-business transformation through effective enterprise management," Eur. J. Inf. Syst., vol. 12, pp. 297-308, 2003.
[25] L. de Boer, J. Harink, and G. Heijboer, "A conceptual model for assessing the impact of electronic procurement," Eur. J. Purchasing Supply Manage., vol. 8, pp. 25-33, 2002.

[26] J. Gansler, W. Lucyshyn, and K. Ross, Digitally Integrating the Government Supply Chain: E-Procurement, E-Finance, and E-Logistics. Washingon, DC: IBM Endowment for the Business of Government, 2003.

[27] T. Puschmann and R. Alt, "Successful use of e-procurement in supply chains," Supply Chain Manage.-Int. J., vol. 10, pp. 122-133, 2005.

[28] W. D. Presutti, "Supply management and e-procurement: Creating value added in the supply chain," Ind. Marketing Manage., vol. 32, pp. 219-226, 2003.

[29] T. Minahan, The E-procurement Benchmark Report. Boston, MA: Aberdeen Group, 2004.

[30] L. Giunipero and R. Eltantawy, "Securing the upstream supply chain: A risk management approach," Int. J. Phys. Distrib. Logist. Manage., vol. 34, pp. 698-713, 2004.

[31] D. Hur, V. A. Mabert, and J. L. Hartley, "Getting the most out of reverse e-auction investment," Omega, vol. 35, pp. 403-416, 2007.

[32] Aberdeen Group, Accounts Payable Supplier Enablement: The Best-inClass Advantage. Boston, MA: Harte-Hanks, 2008.

[33] M. Falk, "ICT-linked firm reorganisation and productivity gains," Technovation, vol. 25, pp. 1229-1250, 2005.

[34] T. Osmonbekov, D. Bello, and D. Gilliland, "Adoption of electronic commerce tools in business procurement: Enhanced buying center structure and processes," J. Bus. Ind. Marketing, vol. 17, pp. 151-166, 2002.

[35] R. Kauffman and H. Mohtadi, "Proprietary and open systems adoption in e-procurement: A risk-augmented transaction cost perspective," $J$. Manage. Inf. Syst., vol. 21, pp. 137-166, 2004.

[36] H. Min and W. P. Galle, "E-purchasing: Profiles of adopters and nonadopters," Ind. Marketing Manage., vol. 32, pp. 227-233, 2003.

[37] C. K. Riemenschneider, D. A. Harrison, and P. P. Mykytyn, "Understanding it adoption decisions in small business: Integrating current theories," Inf. Manage., vol. 40, pp. 269-285, 2003.

[38] R. Agarwal and J. Prasad, "A field study of the adoption of software process innovations byinformation systems professionals," IEEE Trans. Eng. Manage., vol. 47, no. 3, pp. 295-308, Aug. 2000.

[39] K. A. Saeed and S. Abdinnour-Helm, "Examining the effects of information system characteristics and perceived usefulness on post adoption usage of information systems," Inf. Manage., vol. 45, pp. 376-386, 2008 .

[40] C. Lin and G. Pervan, "The practice of IS/IT benefits management in large Australian organizations," Inf. Manage., vol. 41, pp. 13-24, 2003.

[41] S. S. Rao, D. Truong, S. Senecal, and T. T. Le, "How buyers' expected benefits, perceived risks, and e-business readiness influence their e-marketplace usage," Ind. Marketing Manage., vol. 36, pp. 1035-1045, 2007.

[42] A. N. Mishra, P. Konana, and A. Barua, "Antecedents and consequences of internet use in procurement: An empirical investigation of U.S. manufacturing firms," Inf. Syst. Res., vol. 18, pp. 103-120, 2007.

[43] H. Shin, D. A. Collier, and D. D. Wilson, "Supply management orientation and supplier/buyer performance," J. Oper. Manage., vol. 18, pp. 317-333, 2000.

[44] D. Graham, S. Smith, and P. Dunlop, "Lognormal distribution provides an optimum representation of the concrete delivery and placement process," J. Constr. Eng. Manage., vol. 131, pp. 230-238, 2005.

[45] J. Lee, K. Siau, and S. Hong, "Enterprise integration with ERP and EAI," Commun. ACM, vol. 46, pp. 54-60, 2003.

[46] J. P. Baron, M. J. Shaw, and A. D. Bailley, Jr., "Web-based E-catalog Systems in B2B Procurement," Сотmun. ACM, vol. 43, pp. 93-100, 2000

[47] E. Boulianne, "The impact of procurement card usage on cost reduction, management control, and the managerial audit function," Managerial Aud. J., vol. 20, pp. 592-604, 2005.

[48] R. Handfield, Supply Market Intelligence: A Managerial Handbook for Building Sourcing Strategies. Boca Raton, FL: Auerbach, 2006

[49] M. Caridi, S. Cavalieri, G. Diazzi, and C. Pirovano, "Assessing the impact of e-procurement strategies through the use of business process modelling and simulation techniques," Prod. Plann. Control, vol. 15, pp. 647-661, 2004

[50] A. Greasley, "Using process mapping and business process simulation to support a process-based approach to change in a public sector organisation," Technovation, vol. 26, pp. 95-103, Jan. 2006

[51] E. Mohebbi, F. Choobineh, and A. Pattanayak, "Capacity-driven vs. demand-driven material procurement systems," Int. J. Prod. Econ., vol. 107, pp. 451-466, 2007. 
[52] A. Roeder and B. Tibken, "A methodology for modeling inter-company supply chains and for evaluating a method of integrated product and process documentation," Eur. J. Oper. Res., vol. 169, pp. 1010-1029, 2006

[53] K. Vergidis, A. Tiwari, and B. Majeed, "Business process analysis and optimization: Beyond reengineering," IEEE Trans. Syst., Man, Cybern. C, Appl. Rev., vol. 38, no. 1, pp. 69-82, Jan. 2008

[54] J. Berlak and V. Weber, "How to make e-Procurement viable for SME suppliers," Prod. Plann. Control, vol. 15, pp. 671-677, 2004.

[55] I. Davies, P. Green, M. Rosemann, M. Indulska, and S. Gallo, "How do practitioners use conceptual modeling in practice?," Data Knowl. Eng., vol. 58, pp. 358-380, 2006.

[56] A. Groznik, A. Kovačič, and P. Trkman, "The role of business renovation and informatization in e-government," J. Comput., vol. 49, pp. 80-88, 2008

[57] J. Erjavec, M. Gradisar, and P. Trkman, "Renovation of the cutting stock process," Int. J. Prod. Res., vol. 47, pp. 3979-3996, 2008.

[58] F. Persson and J. Olhager, "Performance simulation of supply chain designs," Int. J. Prod. Econ., vol. 77, pp. 231-245, 2002

[59] S. Avery, "Purchasing 2007 salary survey: Purchasing salaries continue their climb," Purchasing, 2007.

[60] C. Chandra and J. Grabis, "Inventory management with variable lead-time dependent procurement cost," Omega, vol. 36, pp. 877-887, 2008.

[61] S. Vachon and R. Klassen, "An exploratory investigation of the effects of supply chain complexity on delivery performance," IEEE Trans. Eng. Manag., vol. 49, no. 3, pp. 218-230, Aug. 2002.

[62] C. S. Tapiero, "Value at risk and inventory control," Eur. J. Oper. Res., vol. 163, pp. 769-775, 2005.

[63] S. Basak and A. Shapiro, "Value-at-risk-based risk management: Optimal policies and asset prices," Rev. Finan. Stud., vol. 14, pp. 371-405, 2001.

[64] K. Dowd, Beyond Value at Risk: The New Science of Risk Management (Wiley Series in Financial Engineering). New York: Wiley, 1998

[65] D. Simchi-Levi, "Managing uncertainty and risk in the supply chain using financial engineering instrument," presented at the MIT Eng. Syst. Div. 2004 Symp., Cambridge, MA.

[66] D. Kent, "Supply chain risk measurement," Supply-Chain Council Risk Management Team, Shangai, China, 2007.

[67] B. Tomlin, "On the value of mitigation and contingency strategies for managing supply chain disruption risks," Manage. Sci., vol. 52, pp. 639657, 2006.

[68] A. Carr and L. Smeltzer, "The relationship between information technology use and buyer-Supplier relationships: An exploratory analysis of the buying firm's perspective," IEEE Trans. Eng. Manag., vol. 49, no. 3, pp. 293-304, Aug. 2002.

[69] G. Reiner and M. Trcka, "Customized supply chain design: Problems and alternatives for a production company in the food industry. A simulation based analysis," Int. J. Prod. Econ., vol. 89, pp. 217-229, 2004.

[70] B. Yang, N. D. Burns, and C. J. Backhouse, "Management of uncertainty through postponement," Int. J. Prod. Res., vol. 42, pp. 1049-1064, 2004.

[71] K. T. Yeo and J. H. Ning, "Managing uncertainty in major equipment procurement in engineering projects," Eur. J. Oper. Res., vol. 171, pp. 123134, 2006.

[72] G. Hamel, Das revolutionäre Unternehmen. (Wer Regeln bricht: Gewinnt). Muenchen, Germany: Econ, 2000.

[73] C. J. Mayer and C. T. Somerville, "Land use regulation and new construction," Reg. Sci. Urban Econ., vol. 30, pp. 639-662, 2000.

[74] J. Harvey, L. Lefebvre, and E. Lefebvre, "Exploring the relationship between productivity problems and technology adoption in small manufacturing firms," IEEE Trans. Eng. Manag., vol. 39, no. 4, pp. 352-358, Nov. 1992.

[75] Hackett Group, "Dow Chemical Company: Supply Risk Management Process Is Key to Improving Safety and Security," in Proc. Third Ann. Europ. Best-Pract. Conf., "Leveraging Synergies: Myth or Reality," May $10-11,2007$.

[76] D. Shi, "A review of enterprise supply chain risk management," J. Syst. Sci. Syst. Eng., vol. 13, pp. 219-244, 2004.

[77] S. Chopra and M. S. Sodhi, "Managing risk to avoid supply-chain breakdown," Sloan Manage. Rev., vol. 46, pp. 53-61, 2004.

[78] M. Faisal, D. K. Banwet, and R. Shankar, "Mapping supply chains on risk and customer sensitivity dimensions," Ind. Manage. Data Syst., vol. 106, pp. $878-895,2006$
[79] T. Kobayashi, M. Tamaki, and N. Komoda, "Business process integration as a solution to the implementation of supply chain management systems," Inf. Manage., vol. 40, pp. 769-780, 2003.

[80] K. McCormack and W. Johnson, Business Process Orientation: Gaining the E-Business Competitive Advantage. Delray Beach, FL: St Lucie Press, 2001.

[81] M. Zhang and M. Tseng, "A product and process modeling based approach to study cost implications of product variety in mass customization," IEEE Trans. Eng. Manag., vol. 54, no. 1, pp. 130-144, Feb. 2007.

[82] E. Bartezzaghi and S. Ronchi, "E-sourcing in a buyer-operator-seller perspective: Benefits and criticalities," Prod. Plann. Control, vol. 16, pp. 405412, 2005.

[83] M. Bensaou and N. Venkatraman, "Inter-organizational relationships and information technology: A conceptual synthesis and a research framework,” Eur. J. Inf. Syst., vol. 5, pp. 84-91, 1996.

[84] G. Premkumar, K. Ramamurthy, and C. S. Saunders, "Information processing view of organizations: An Exploratory examination of fit in the context of interorganizational relationships," J. Manage., vol. 22, pp. 257294,2005

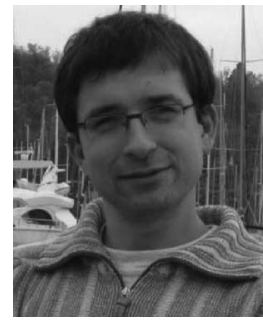

Peter Trkman received the M.Sc. and Ph.D. degrees in management information systems from the University of Ljubljana, Ljubljana, Slovenia.

$\mathrm{He}$ is currently an Assistant Professor in the Faculty of Economics, University of Ljubljana. His research interests include technology adoption, egovernment, and various aspects of the supply chain, business process, and operations management. $\mathrm{He}$ has participated in several national and international projects (both research and consulting). He is the author or coauthor of more than 60 papers/book chapters, including papers in the Computers and Operations Research, the European Journal of Operational Research, the Government Information Quarterly, the International Journal of Information Management, the International Journal of Production Economics, the International Journal of Production Research, the Journal of Computer Information Systems, the Online Information Review, the Supply Chain Management-An International Journal, the Technology Forecasting and Social Change, and the Telecommunications Policy.

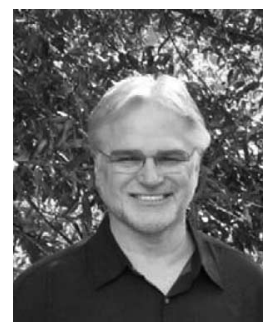

Kevin McCormack received the degrees in Chemistry, Engineering, MBA, and DBA.

He is currently the President of the DRK Research, Raleigh, NC. He is also associated with various Universities such as Babson College, NC State, and the University of Oklahoma. He is the Master Instructor for Supply Chain Risk with the Supply Chain Council. He has more than 30 years of business leadership, engineering, teaching, research, and consulting experience in the areas of information technology, operations management, and supply chain management. He has also developed and delivered courses in information technology, HR, operations management, and supply chain management at the graduate and undergraduate level both in U.S., China, and Europe. He is the author or coauthor of five books and more than 100 articles in the Quality Progress, the Business Process Management Journal, the Supply Chain Management, Benchmarking: A International Journal, and the Supply Chain Management Review. He is also a Judge for the Manufacturer of the Year Award for the state of Alabama, home of various international manufacturers' locations (Honda, Mercedes, Lockheed, BASF, Nucor, U.S. Steel, and Siemens Automotive) as well as dozens of defense and automotive suppliers. 